\title{
Diretrizes para implantação da governança de tecnologia da informação no setor público brasileiro à luz da Teoria Institucional
}

José Geraldo Loureiro Rodrigues e João Souza Neto

\section{Introdução}

A governança de tecnologia de informação (GTI), no âmbito do setor público, não apresenta, conceitualmente, diferenças relevantes em relação àquela aplicada no setor privado. Para Rocheleau e Wu (2002), a diferença fundamental é que o setor público fornece "bens públicos", não serviços para venda. O aspecto financeiro, que envolve as organizações do setor privado, permite, com mais facilidade, a aquisição de tecnologias de ponta, uma vez que o investimento proporciona uma vantagem competitiva e subsequente ganho financeiro para a organização. Porém, como constatado pelo Tribunal de Contas da União (CaValCanti, 2008, p. 14), as fragilidades no setor público brasileiro denotam a falta da governança de TI, e a principal causa seria a ausência da boa governança corporativa.

De fato, além das irrefutáveis evidências apontadas pelo Tribunal de Contas da União, corroboram o entendimento sobre a ausência de GTI nas organizações públicas do Brasil as características das atividades inerentes aos gestores 
de TI nesse setor, mais apropriadas ao conceito de gerenciamento de TI, seja pela baixa representatividade dos mandatários dessas unidades em relação à autoridade ministerial, seja pelo seu foco, que é interno e voltado à administração dos processos e serviços de TI, com pouca ou nenhuma influência na estratégia organizacional.

Por outro lado, apesar das determinações dos órgãos de controle externo, como o Tribunal de Contas da União (TCU), raras são as iniciativas estruturadas de implantação da governança de TI nas organizações do setor público. Desse modo, fica patente que as mudanças não acontecem pela simples publicação de uma instrução normativa, ou pela determinação formal de um órgão de controle para que as boas práticas e procedimentos de governança de TI sejam incorporados e utilizados. Num ambiente em que prevalecem valores culturais e mitos construídos em décadas de história, a legitimação das orientações é fator determinante para o sucesso dos projetos de melhoria de processos.

A Teoria Institucional, por meio do isomorfismo coercitivo, mimético e normativo, esclarece as dificuldades de implantação da GTI no setor público brasileiro, indicando que a necessidade de legitimação das decisões, como salvaguarda perante questionamentos das instâncias de controle, faz com que as mudanças e inovações aconteçam lentamente e à medida que os níveis operacionais das áreas de TI as incorporem em sua cultura e aos valores institucionais.

Assim, o objetivo deste artigo é a apresentação de diretrizes para implantação da governança de TI no setor público brasileiro, de modo sustentável, que considere as características culturais e ambientais, bem como a busca por legitimidade nas decisões, base do isomorfismo institucional. Esse conjunto de orientações deve considerar os diferentes níveis de maturidade das áreas de TI nas organizações públicas brasileiras e a forte influência dos órgãos de controle na determinação de padrões de comportamento dos mandatários das áreas de TI.

\section{Governança e gerenciamento da'TI}

O termo "governança de TI" foi usado por Loh e Venkatraman (1992 apud BROWN \& GRANT, 2005, p.698) e por Henderson e Venkatraman (1999, p.474), para descrever o conjunto de mecanismos (e.g. parcerias, joint ventures, alianças estratégicas etc.) para assegurar a obtenção de capacitação em TI. Mas o termo só voltou a ser registrado na literatura acadêmica ao final dos anos 1990, quando Brown (1997 apudBrown \& GRANT, 2005, p.698) e Sambamurthy e Zmud (1999, p.1) introduziram, em seus artigos, a noção de IS governance frameworks e depois IT governance frameworks, respectivamente.

Para Peterson (2004, p.41), "a governança de TI é um tema mal definido, com limites obscuros e pouco compreendido pelos profissionais de TI". Mesmo que o termo esteja se tornando rapidamente popular entre os profissionais de TI, seu conceito, frequentemente, é mal empregado ou compreendido pelos mesmos (MCLANE, 2003 apud LunARDi, 2008, p.34).

A falta de clareza do conceito de governança de TI não é surpreendente, dado que Sistemas de Informação é uma disciplina relativamente nova, que surgiu de forma orgânica a partir de uma variedade de diferentes disciplinas, incluindo, entre outras, as Ciências Sociais e a Ciência da Computação (WebB, P.; Pollard, C. \& Ridley, G., 2006, p.1). A mais recente definição vem da ISO/IEC 38500 (2008, 
p. 3), segundo a qual governança de TI é o sistema pelo qual a atual e a futura utilização da TI são dirigidas e controladas, envolvendo a avaliação e orientação da utilização da TI para apoiar a organização no atendimento de suas metas, incluindo as estratégias e políticas de utilização da TI dentro dessa organização.

Há pouca literatura que diferencie governança de TI de gerenciamento da TI. Como consequência, os dois conceitos são muitas vezes considerados sinônimos, embora sejam diferentes entre si (SOHAL \& Fitzpatrick, 2002 apud Sethibe, T.; Campbell, J. \& Mcdonald, C., 2007, p. 835).

Segundo o Dicionário Houaiss, conceitualmente "governança" significa ato de governar, governação, governo. Por outro lado, "gestão" é o ato de gerir, administrar, e a acepção da palavra "gerência" significa ação de gerir, gerenciamento. Os termos gestão e gerência estão muito próximos conceitualmente e somente analisando a etimologia das palavras é que poderemos identificar a tênue diferença.

Gestão vem do latim gestio, ónis - ação de administrar, de dirigir, gestão. Gerência seria o particípio presente do latim gerère fazer, produzir, criar, gerir.

Desse modo, gestão estaria mais próxima aos conceitos de direção de uma entidade, enquanto gerência estaria mais próxima aos conceitos de supervisão de uma unidade.

Weill (2004, p. 2) corrobora essa análise, ao afirmar que "a governança de TI não se preocupa com 'quais' decisões foram tomadas, isto é gerenciamento da TI. A governança de TI está sistematicamente atenta, determinando 'quem' toma cada tipo de decisão (a decisão correta), 'quem' contribui para as decisões (a entrada de dados correta) e 'como' essas pessoas, ou grupos, são monitorados em seus papéis".
Peterson (2004, p. 44) também reforça esse entendimento ao registrar que o gerenciamento da TI foca na eficiência e eficácia do fornecimento de produtos e serviços de TI no âmbito interno, bem como no gerenciamento atual das operações de TI; e a governança de TI está concentrada em dar suporte e melhorar o desempenho das atividades da corporação e, ainda, em transformar e posicionar a TI

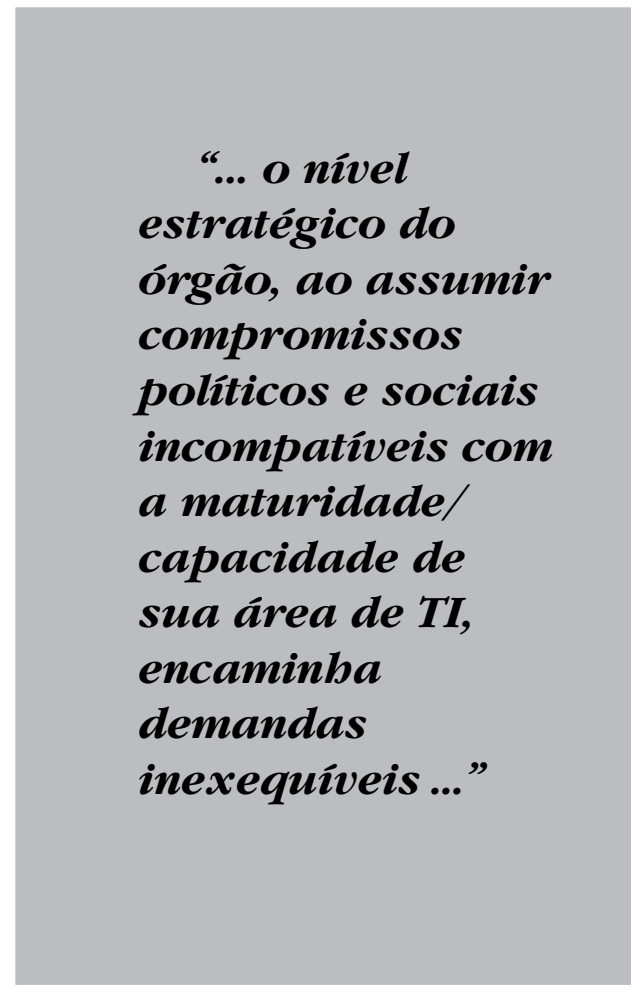

de modo a habilitá-la aos futuros desafios nos negócios.

Assim, o gerenciamento da TI, seus elementos, produtos entregues e serviços prestados podem ser delegados a um provedor externo, enquanto a governança de TI é exclusiva da organização, uma vez que direção e controle da TI não podem ser delegados ao mercado (Peterson, 2004, p. 44). 
A norma ISO/IEC 38500 (2008, p. 5) registra a existência de confusão entre os conceitos de governança e gerenciamento de TI, mas esclarece que gerenciamento no contexto de TI é o sistema de controle e processos requeridos para se alcançar objetivos estratégicos em conformidade com o corpo governante da organização.

\section{Diferenças entre a governança de TI do setor público e do setor privado}

Para Vinten (2002 apud Ali \& GREeN, 2007 , p. 42), as organizações do setor público há muito reconhecem a importância da efetiva governança de TI para o seu sucesso. Contudo, poucas pesquisas têm sido realizadas para examinar quais mecanismos contribuem para estabelecer essa efetividade dentro de organizações públicas. De fato, não foram identificadas conceituações para a governança de TI em organizações públicas, o que pode indicar semelhanças entre a aplicação do conceito no setor público e no setor privado.

A literatura sobre GTI destaca alguns basilares nas organizações que governam suas áreas de tecnologias: alinhamento estratégico entre a TI e os negócios, entrega de valor pela TI à organização, gerenciamento dos riscos relacionados à TI, gerenciamento do desempenho da TI, gerenciamento de recursos e controle, e responsabilização pelas decisões de TI (Grembergen, W.; Haes, S. \& Guldentops, E., 2004, p. 7; Itgi, 2003, p. 21; WeBB et al., 2006, p. 7; FLETCHer, 2006, p. 34). Com foco nesses basilares, não se identificam diferenças entre a governança de TI aplicável em organizações do setor público e do setor privado. Reforça essa ausência de diferenças a publicação da Norma Internacional ISO/IEC 38500 (2008), que trata da governança corporativa e governança de TI, definindo ser plenamente aplicável aos setores público e privado, inclusive os conceitos.

Utilizando-se dos estudos de Barrett (2001, p. 12) sobre as diferenças entre organizações públicas e privadas, projeta-se que a governança de TI em organizações do setor público sofre a influência do ambiente político - com foco em verificações -, e dos sistemas de valores, que enfatizam questões éticas e cumprimento de normas e dispositivos legais. Pode-se, então, afirmar que os modelos de governança de TI nos setores público e privado são semelhantes em seus pilares básicos, mas muito diferentes nos aspectos ambientais que envolvem as características das pressões institucionais externas e internas. De fato, as pressões institucionais representam importante fonte de demandas para as áreas de TI nas organizações públicas, e as pressões financeiras e de mercado, inerentes ao setor privado, são forças propulsoras de demandas nas empresas e firmas.

A divergência maior entre o setor público e o privado se encontra na forma como os agentes responsáveis pela governança reagem a essas pressões. No setor privado, o foco está na reversão do resultado financeiro, na busca pela remuneração do capital investido, para sobrevivência da empresa. No setor público, busca-se a salvaguarda das decisões e legitimidade das ações; a sobrevivência da organização depende do cumprimento de cerimoniais, ritos legais e mitos culturais, dado que inexistem indicadores de resultado.

\section{Teoria Institucional}

A Teoria Institucional teve seu início com os postulados de Meyer e Rowan (1977, p. 340) sobre institucionalismo, segundo os quais as organizações são levadas a 
incorporar as práticas e procedimentos definidos pelos conceitos que predominam no ambiente organizacional e que estejam institucionalizados na sociedade. Assim, as estruturas formais de muitas organizações refletem os mitos de seu ambiente institucionalizado, em vez das reais necessidades das atividades de trabalho.

Estruturas formais que celebram mitos institucionalizados diferem das estruturas que buscam atuar de forma eficiente. Nesses casos, o cumprimento de ritos cerimoniais é mais significante que os resultados concretos (MERTON, 1940; MARCH \& Simon, 1958 apud Meyer \& Rowan, 1977, p. 355).

Para Scott (1987, p. 493), a sabedoria implícita na abordagem da Teoria Institucional é a de reconhecer, desde o início, que não existe uma, mas diversas variantes. Nesse sentido, Jacobson (2009, p. 6) afirma terem sido feitas tentativas para reunir as variantes em uma teoria geral e, citando Greenwood e Hinings (1996, p. 1023), exemplifica a combinação entre o velho institucionalismo, com ênfase no conflito de interesses, competitividade e influência social, e o novo institucionalismo, com seu foco na legitimidade e incorporação de áreas organizacionais, resultando no comumente chamado neoinstitucionalismo.

Para Greenwood e Hinings (1996, p. 1023), a Teoria Neo-institucional é fraca em analisar a dinâmica interna da mudança organizacional e, por consequência, é omissa sobre o motivo pelo qual algumas organizações adotam uma mudança radical, enquanto outras não, apesar de experimentarem as mesmas pressões institucionais. Para os autores, essa teoria contém insights (compreensões) e sugestões que, elaborados, fornecem um modelo de mudança que liga o contexto organizacional e a dinâmica intraorganizacional. Assim, a Teoria Institucional não é normalmente vista como uma teoria de mudança organizacional, mas, geralmente, é considerada uma explicação da similaridade (isomorfismo) e estabilidade de arranjos organizacionais em uma dada população ou área de interesse organizacional.

\section{Isomorfismo}

O conceito que melhor representa esse processo de homogeneização é o isomorfismo. Para Hawley (1968 apud Dimaggio \& Powell, 1983, p. 149), isomorfismo é um processo restritivo que força uma unidade em uma população a assemelharse a outras unidades, que enfrentam o mesmo conjunto de condições ambientais. Tal conceito é uma importante ferramenta para se entender as políticas e o cerimonial que permeiam a vida das modernas organizações. Existem três mecanismos por meio dos quais as mudanças isomórficas institucionais ocorrem: isomorfismo coercitivo, que decorre de influência política e do problema da legitimidade; isomorfismo mimético, resultante da padronização de respostas à incerteza; e isomorfismo normativo, associado com profissionalização (Dimaggio \& Powell, 1983, p. 150).

$\mathrm{O}$ isomorfismo coercitivo resulta de pressões formais e informais exercidas sobre organizações por outras organizações das quais elas dependem, e pelas expectativas culturais da sociedade em que as organizações atuam (Dimaggio \& Powell, 1983, p. 150). Ou seja, é o mecanismo pelo qual as organizações se conformam às regulamentações governamentais e às expectativas culturais, capazes de impor uniformidade às organizações.

O isomorfismo mimético ocorre quando tecnologias organizacionais são pobres, 
quando objetivos são ambíguos ou quando o ambiente cria incertezas simbólicas, levando as organizações a modelarem-se em outras. A incerteza é uma poderosa força para incentivar a imitação (DIMAGGIO \& Powell, 1983, p. 151).

Já o isomorfismo normativo tem origem na profissionalização, educação formal, disseminação de conhecimento por especialistas e na definição de métodos de trabalho para estabelecimento de uma base cognitiva e de legitimidade (Dimaggio \& Powell, 1983, p. 152). Para os autores, uma importante fonte de isomorfismo normativo é a seleção de pessoal, pois, dentro de muitas áreas organizacionais, a seleção ocorre por meio de contratação de indivíduos a partir de empresas do mesmo setor, por intermédio do recrutamento de pessoal de uma pequena gama de instituições de formação e, por fim, considerando requisitos de perfil para funções específicas. Muitos profissionais de carreira são tão fortemente enquadrados, na entrada e em toda a progressão de carreira, que os indivíduos no início e no topo são virtualmente indistinguíveis.

Para Meyer (1979 apud Dimaggio \& Powel, 1983, p. 149) e Fennell (1980 apud Dimaggio \& Powell, 1983, p. 149), há dois tipos de isomorfismo: o competitivo e o institucional. O isomorfismo competitivo, segundo Hannan e Freeman (1977 apud Dimaggio \& Powell, 1983, p. 149), é um sistema racional que enfatiza a competição de mercado, mudança de nicho e avaliação de aptidão, comuns nas áreas de livre mercado e competição. Nesse caso, as organizações copiam produtos, procedimentos e serviços, assemelhando-se entre si durante o processo de competição pelo mercado.

$\mathrm{O}$ isomorfismo institucional, para Aldrich (1979 apud Dimaggio \& Poweld, 1983, p. 149), é um conceito útil para entender as políticas e cerimoniais existentes em várias organizações que competem entre si, não apenas por recursos e clientes, mas por poder político e legitimidade institucional, com foco em objetivos sociais e econômicos - caso comum às organizações do setor público ou organizações presentes em segmentos com baixa competitividade.

Para Meyer e Rowan (1977, p. 340), não é novidade que as organizações sejam estruturadas em conformidade com as características de seus ambientes - ou área de negócio de que a organização participa - e tendam a se tornarem isomórficas com eles. Uma explicação para o isomorfismo é que organizações se tornam idênticas com o ambiente de que participam devido às interdependências técnicas e ao intercâmbio de conhecimento existente. Do ponto de vista de Parsons (1956 apud MEYER \& RowAN, 1977, p. 346) e de Udy (1970 apud MEYer \& Rowan, 1977, p. 346), as organizações são fortemente condicionadas pelas características gerais dos ambientes institucionais de que participam e, por conseguinte, pelas próprias instituições participantes desse ambiente.

Por outro lado, enfatizando aspectos que envolvem as mudanças em organizações, DiMaggio e Powell (1983, p. 147) deram relevante impulso à teoria, reforçando o conceito de isomorfismo, segundo o qual as organizações podem tentar mudar constantemente, mas, depois de certo nível de estruturação de uma determinada área organizacional, o efeito agregado de cada mudança leva à homogeneidade dentro dessa área. Para os autores, as mudanças nas estruturas organizacionais deixaram de ser impulsionadas pela concorrência e necessidade de eficiência, resultando em processos que tornam as organizações mais similares, sem necessariamente serem mais 
eficientes. Ou seja, as abordagens organizacionais altamente estruturadas provêm de um contexto no qual o esforço individual para tratar racionalmente a incerteza e restrições frequentemente leva à homogeneidade em estrutura, cultura e resultado.

Uma vez que diferentes organizações, de mesma área de negócios, se estruturam em ambientes altamente institucionalizados, forças poderosas emergem, levando essas organizações a tornarem-se similares entre si. Essas entidades podem tentar mudar metas ou desenvolver novos processos, mas os atores que tomam decisões constroem à sua volta um ambiente que restringe essas mudanças, frustrando inovadores individuais que buscam a melhoria no desempenho do processo (Dimaggio \& Powell, 1983, pp. 148-149). Para esses autores, o grau de diversidade se reduz por meio do efeito do intercâmbio de conhecimento em busca de legitimidade no ambiente institucional.

\section{Legitimidade}

Meyer e Rowan (1977, p. 355) esclarecem que dois problemas comuns surgem em organizações cujo sucesso depende preliminarmente de isomorfismo com as regras institucionalizadas. Em primeiro lugar, as atividades técnicas e as exigências por eficiência criam conflitos e incoerências no esforço institucional de uma organização para estar em conformidade com as regras cerimoniais de produção. Em segundo lugar, dado que essas regras são transmitidas por meio de mitos que têm as mais distintas origens, umas regras estabelecidas podem entrar em conflito com outras existentes. Assim, essas inconsistências criam dificuldades para a eficiência, a coordenação e o controle.

Para ultrapassar essas fronteiras, há de se buscar a legitimidade das iniciativas, pois a incorporação de elementos já institucionalizados proporciona uma salvaguarda para as decisões e atividades, protegendo a organização de ter sua conduta questionada. A organização torna-se, em uma palavra, legitimada, e ela usa sua legitimidade para reforçar o seu apoio e assegurar a sua sobrevivência (MEYER \& ROWAM, 1977, p. 349).

Já para Pfeffer (1982 apud EISENHARD, 1988, p. 492), a ideia-chave por trás da

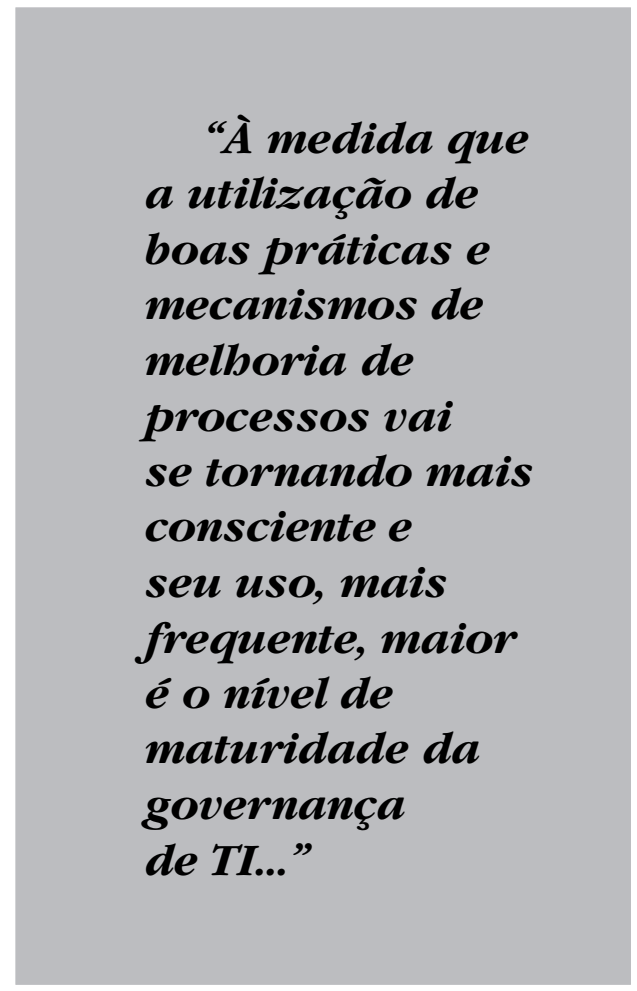

institucionalização é que muitas ações organizacionais refletem uma maneira de fazer coisas que evolui ao longo do tempo e torna-se legitimada dentro de uma organização ou ambiente. Para Zucker (1977 apud EISENHARDT, 1988, p. 492), essa legitimidade faz com que coisas sejam feitas de uma certa maneira, pelo simples fato de haver se tornado o único modo aceitável de fazê-las. 
Situação atual da governança de TI no governo brasileiro

Os reiterados registros de fragilidades na governança da área de TI dos órgãos e entidades da APF, efetuados pelo Tribunal de Contas da União, por meio de diversos acórdãos (TCU, 2012, 2010, 2008 a, b), demonstram que a situação da governança de TI na APF ainda se encontra em estado precário. O Acórdão 2584/2012 (TCU, 2012) afirma que houve evolução na situação da governança de TI na administração pública federal em relação ao último levantamento (2010), contudo, há ainda oportunidades de melhoria.

Com relação aos mecanismos básicos para a alta administração dos órgãos da APF governar a TI de forma efetiva (e.g. pela designação de um comitê estratégico de TI, pela definição de metas de desempenho e pelo monitoramento desse desempenho), o quadro, segundo o TCU, ainda se encontra em nível baixo de maturidade. Os dados levantados em 2012 demonstraram evolução da estrutura de governança de TI das instituições públicas federais, e sugerem que sua alta administração passou a compreender melhor a importância dessa estrutura para o seu negócio. Contudo, é preocupante que $46 \%$ dos avaliados tenham declarado não se responsabilizar pelas políticas de TI, já que essas políticas visam a garantir que o uso da TI contribua para melhor desempenho da instituição.

Quanto à apuração realizada, verificouse que, em 2012, 54\% das instituições estabeleceram objetivos de desempenho de TI, contra 43\% em 2010, revelando melhora em relação ao levantamento anterior. Entretanto, $46 \%$ de instituições que não definiram esses objetivos ainda são percentual alto, levando em consideração o risco associado à ausência dessas diretrizes. A situação piora quando se observa que apenas 37\% dos avaliados estabeleceram indicadores de desempenho e somente $23 \%$ acompanham os indicadores de benefícios dos principais sistemas de informação. Em resumo, esses números sugerem que a maioria das instituições públicas federais tem dificuldade em perseguir seus objetivos, uma vez que nem chegam a definir os indicadores que serão a referência para avaliar o seu alcance. Além disso, poucos são os órgãos que tomam decisões com base nos benefícios de negócio oriundos de seus principais sistemas de informação. Dessa forma, sob a ótica da eficiência e da efetividade, o alcance dos resultados institucionais tende a ser prejudicado (TCU, 2012).

Uma questão crítica vivida hoje pelas instituições públicas federais é a da precariedade ou completa ausência da gestão de risco. O TCU (2012, p. 17-18) afirma:

Entre os índices, causa preocupação especial o baixo percentual de instituições que realizam análise de risco, que passou de $17 \%$ para $10 \%$. Ou seja, 90\% das instituições públicas federais ainda não realizam esse tipo de análise. Deve-se ressaltar que um processo de análise de riscos é indicador da maturidade da gestão de determinada instituição. De início, esse processo recebe como insumos o mapa dos processos críticos e o inventário de ativos, físicos e de informação, necessários a esses processos. Sem esses elementos básicos, qualquer gestão de riscos é, na melhor das hipóteses, incompleta. Além disso, o resultado da análise de riscos é insumo essencial para outros processos, como a gestão de continuidade do negócio. Dessa forma, dado que apenas $10 \%$ das organizações declararam realizar análise de 
riscos, pode-se concluir que a gestão da tecnologia da informação ainda se encontra em nível baixo de maturidade na administração pública. Entre os potenciais efeitos desse quadro, temse: ineficiência na aplicação dos recursos; desconhecimento dos riscos aos quais os processos críticos da instituição estão expostos; e ausência de critérios sólidos de planejamento e de priorização das ações de segurança da informação.

Outro ponto importante é o do gerenciamento de serviços de TI. Percebe-se que a situação continua crítica. Verifica-se, por exemplo, que 73\% das instituições não possuem catálogo dos serviços de TI a serem ofertados à sua clientela. Em um cenário ainda mais crítico, observa-se que 98\% das organizações públicas federais sequer estabelecem acordos de nível de serviços (ANS) entre a área de TI e suas áreas clientes, situação que prejudica a avaliação dos serviços de TI e tende a afetar a qualidade dos resultados esperados (TCU, 2012).

\section{Uma proposta de diretrizes de GTI no setor público à luz da Teoria Institucional}

Com base nas análises e diagnósticos apresentados neste artigo, entende-se que a governança de TI, para ser implantada no setor público brasileiro, requer a adaptação dos processos para considerar o isomorfismo institucional como orientador da legitimação das práticas e procedimentos aplicáveis às áreas de TI dos órgãos públicos.

Assim, o estabelecimento de diretrizes para implantação da governança de TI na administração pública federal passa pelo entendimento do funcionamento dessa governança à luz da Teoria Institucional e do isomorfismo institucional que a caracteriza. A Teoria Institucional não é normalmente vista como uma teoria de mudança organizacional, mas, geralmente, é considerada uma explicação da similaridade (isomorfismo) em uma população que atua no mesmo ambiente, ou ainda, em uma área de interesse organizacional (GREENWOOD \& Hinings, 1996, p. 1023). Desse modo, os conceitos inerentes a essa teoria podem explicar como se processam as mudanças em ambientes altamente institucionalizados, comuns às organizações do setor público brasileiro.

Conforme já dito, segundo a Teoria Institucional, as organizações são levadas a incorporar as práticas e procedimentos definidos pelos conceitos que predominam no ambiente organizacional e que estão institucionalizados no ambiente em que atuam. Assim, as estruturas formais de muitas organizações refletem os mitos de seu ambiente institucionalizado, em vez das reais necessidades das atividades de trabalho (MEyer \& Rowan, 1977, p. 340).

As estruturas formais que celebram mitos institucionalizados diferem das estruturas que buscam atuar de forma eficiente. Nesses casos, o cumprimento de ritos cerimoniais incorporados pelas organizações é mais significante que a obtenção de resultados concretos (Merton, 1940; March \& Simon, 1958 apud Meyer \& ROWAN, 1977, p. 355).

Assim, a simples introdução, no setor público, dos modelos e boas práticas do setor privado, sem considerar as características das organizações públicas e suas necessidades de legitimar procedimentos e ações, gera mais resistência do que apoio do nível operacional. A legitimidade, inerente ao modelo institucional, faz com que as coisas sejam feitas de certa maneira, pelo 
simples fato de haver se tornado o único modo aceitável de fazê-las (Zucker, 1977 apud EISENHARDT, 1988, p. 492).

Como consequência das pressões institucionais incompatíveis com a realidade das áreas de TI, ou seja, de exigências superiores à sua capacidade de atendimento, os gestores dessas áreas buscam o cumprimento do rito coercitivo, sem compromisso com a efetividade de seus resultados. A falta de resultados efetivos e a tentativa de cumprimento de determinações independentemente do nível de maturidade/capacidade da equipe fazem com que as áreas de TI incorram em novas falhas, gerando mais mitos burocráticos e ritos cerimoniais que podem levar à estagnação das atividades do órgão. Para Machado da Silva e Gonçalves (1999 apud Rossetto \& Rossetto, 2005, p. 6), as organizações interagem com o seu ambiente em busca de legitimidade, fazendo com que as decisões tomadas sejam influenciadas pela conformidade às regras, normas e crenças (mitos) institucionalizadas, de forma independente dos critérios de eficiência, distanciando a estrutura formal das práticas adotadas.

Da mesma forma, o nível estratégico do órgão, ao assumir compromissos políticos e sociais incompatíveis com a maturidade/capacidade de sua área de TI, encaminha demandas inexequíveis de serem cumpridas se respeitada a conformidade com as normas, procedimentos e boas práticas previstos para a área de TI. O resultado desse contrassenso é o desalinhamento da área de TI com os objetivos estratégicos do órgão, ou o descumprimento de determinações normativas e legais, ou ambos.

Por essa justa medida, entende-se que a implantação da governança de TI no setor público brasileiro não acontecerá por determinação de lei, decreto presidencial, acórdão do Tribunal de Contas ou por portaria ministerial, do mesmo modo que, no setor privado, não se implanta uma governança de TI pela simples vontade do proprietário/ acionista. A área de TI deve ter os meios (recursos) e a capacidade (competência e habilidade) para incorporar as mudanças organizacionais necessárias. Para Lunardi (2008, p. 21), independentemente de estarem ou não engajadas formalmente no processo de implementação da governança de TI, as organizações apresentam níveis de maturidade quanto à utilização dessas práticas no seu dia a dia. Algumas desenvolvem seu próprio modelo, outras acabam implementando uma ou mais metodologias ou frameworks já consolidados no mercado (como o Cobit e o Itil); e também existem aquelas organizações cujo processo de governança ainda não é formalizado, utilizando, entretanto, algumas dessas práticas em maior ou menor grau.

Em ambientes altamente institucionalizados, em que inexistem indicadores de resultado e prevalecem metas ambíguas ou inexequíveis, as organizações tendem à homogeneização como salvaguarda das ações e decisões dos gestores, e sobrevivência da organização (MEYER \& RowAM, 1977).

Assim, o efeito do intercâmbio de conhecimento, em busca de legitimidade no ambiente institucional, levará à redução do grau de diversidade, tornando as organizações similares em seus procedimentos e atividades (Dimaggio \& Powell, 1983).

Essa tendência à homogeneização no setor público contribui para replicação de modelos e boas práticas de governança de TI. A necessidade de incorporação de práticas já legitimadas agiliza as mudanças, resultando em melhorias nos processos de trabalho e, por consequência, na governança da área de TI. Para Machado da Silva 
e Fonseca (1993 apud RossetTo \& RossetTo, 2005, p. 6), as organizações são levadas a assumirem uma postura isomórfica em relação às organizações líderes em seu ambiente, como forma de autodefesa em relação a problemas que não conseguem resolver por seus próprios meios. Então, adotam processos semelhantes aos de outras organizações, a fim de favorecer o seu funcionamento a partir de regras socialmente aceitas.

Desse modo, é possível afirmar que a legitimidade, maturidade e melhoria de processos estão intervinculadas entre si. Assim, para melhoria de processos, há de se elevar a maturidade, por meio da introdução de modelos e práticas já legitimadas em organizações do setor público.

$\mathrm{O}$ isomorfismo institucional seria o conceito que melhor representaria essa busca pela homogeneização e legitimidade das decisões e ações. Assim, para a adequada (e legítima) implantação da governança de TI no setor público brasileiro, seria necessária a adoção de mecanismos baseados no isomorfismo institucional. Então, a partir dos conceitos de DiMaggio e Powell (1983, p. 150), apresentam-se os seguintes exemplos:

- Isomorfismo mimético - as mudanças decorrem da reprodução de boas práticas e procedimentos de outros órgãos com características semelhantes e nível de maturidade mais elevado. A validação da boa prática pelos órgãos normatizadores e de controle, bem como a ampla divulgação dos bons resultados se tornam elementos de legitimação do órgão e do procedimento;

- Isomorfismo normativo - as mudanças emanam dos processos de capacitação e treinamento de agentes públicos, de modo a elevar o nível de maturidade do órgão. Esses agentes podem atuar, inclusive, como disseminadores das melhorias;
- Isomorfismo coercitivo - as mudanças decorrem de determinações internas ou externas que consideram as peculiaridades e maturidade dos agentes responsáveis pela atividade. Essas determinações devem servir de balizadores medianos, pois se pautam em procedimentos já legitimados.

À medida que a utilização de boas práticas e mecanismos de melhoria de processos vai se tornando mais consciente e seu uso, mais frequente, maior é o nível de

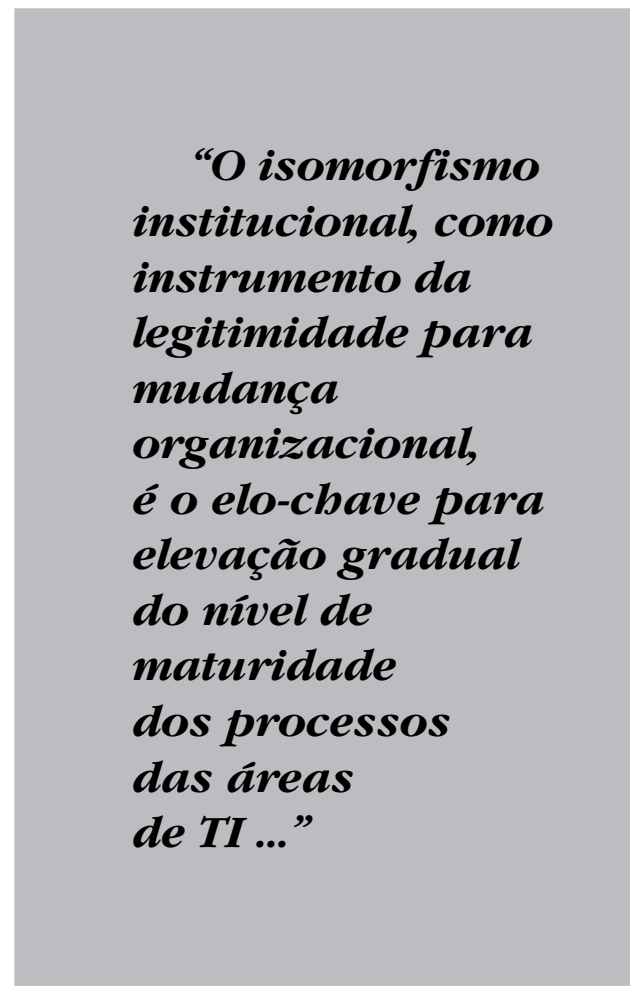

maturidade da governança de TI, tendo como um dos seus principais benefícios a melhor compreensão dos investimentos realizados e a verificação se os mesmos vêm atingindo os resultados esperados (Grembergen et al., 2004).

Desse modo, a elevação gradativa dos níveis de maturidade dos processos da área de TI, utilizando-se de mecanismos 
isomórficos institucionais, pode ser a maneira mais adequada para implantação da governança da tecnologia da informação nas organizações do setor público. Enfatiza-se que nem todas as áreas de TI das organizações públicas chegarão ao nível máximo de maturidade e capacidade, pois as necessidades corporativas dos órgãos são diferentes, mas a complexidade dos processos suportados e os riscos inerentes às atividades da organização darão a justa medida para o nível de maturidade necessário.

A legitimidade e a maturidade são elementos-chave para transposição dos problemas institucionais relacionados com a mudança institucional e, por consequência, para implantação da governança de TI no setor público brasileiro.

\section{Diretrizes para implantação da governança de TI}

As pesquisas demonstram que não há uma forma ideal de estruturar a TI, uma vez que a solução para qualquer organização é contingenciada por fatores como: tamanho da organização, ramo de atuação, localização geográfica, estrutura organizacional, estratégia e natureza da organização, entre outros (BROWN \& Grant, 2005, p. 703).

Também, segundo Haes e Grembergen (2008, p. 24), o desenvolvimento de um modelo de GTI em alto nível não garante o funcionamento da governança na organização, pois a concepção de um modelo de GTI é apenas o primeiro passo, sua implantação como uma solução sustentável é o maior desafio.

Assim, propõe-se um conjunto de diretrizes para implantação da governança de TI na administração pública federal, envolvendo a incorporação de ações isomórficas institucionais para legitimação dos procedimentos e decisões dos gestores de TI, de forma que suas equipes possam amadurecer seus processos, enquanto se capacitam e se habilitam na sustentação da boa prática adotada. O isomorfismo institucional, como instrumento da legitimidade para mudança organizacional, é o elo-chave para elevação gradual do nível de maturidade dos processos das áreas de TI e, consequentemente, da implantação das boas práticas de GTI existentes.

As diretrizes representam um conjunto de boas práticas e seguem o postulado de Haes e Grembergen (2008, p. 24), segundo o qual a governança de TI pode ser implantada usando uma mistura de várias estruturas, processos e mecanismos de relacionamento:

- Estruturas de GTI incluem dispositivos e mecanismos estruturais (formais) para conectar e permitir contatos horizontais entre negócios e as funções de gerenciamento de TI (tomada de decisões).

- Processos de GTI referem-se à formalização e à institucionalização da tomada de decisão estratégica de TI ou dos procedimentos de controle de TI.

- Os mecanismos de relacionamento tratam da ativa participação e colaboração entre os executivos da corporação, os gestores de TI e os gestores de negócios.

\section{Estrutura da GTI}

As estruturas da GTI envolvem a organização e o posicionamento da área de TI na estrutura hierárquica da organização, bem como a clara definição de papéis e responsabilidades dos cargos que compõem essa estrutura (HAEs \& GREMBERGEN, 2008, p. 24). 
$1^{a}$ Diretriz - Criação do segmento de governança de TI na estrutura dos órgãos

Quando se discute a implantação da governança de TI nas organizações públicas brasileiras, a concepção básica é a participação representativa da TI, no nível estratégico da organização. Para Weill e Ross (2006, p. 2), a GTI reflete princípios amplos de governança corporativa, definindo responsabilidades sobre a gestão e uso dos recursos de TI como suporte aos objetivos de negócios.

Assim, não basta o reposicionamento hierárquico da área de TI, mantendo-se o viés operacional atual; há de se ir além. A área de TI deve ganhar representatividade no nível estratégico da organização, por meio da criação de uma função de ligação da Secretaria-Executiva do Ministério (ou presidência do órgão) com a atual Coordenação-Geral de TI.

Uma das possíveis implementações seria a criação de uma subsecretaria de TI, tendo como função principal as atividades inerentes à governança de TI. A Figura 1 apresenta a proposta de estrutura hierárquica para governança de TI no setor público brasileiro.

Uma definição clara e não ambígua dos papéis e responsabilidades das partes envolvidas é pré-requisito crucial para uma boa governança de TI (GREMBERGEN et al., 2004, p. 21). Assim, as responsabilidades atribuídas a esse subsecretário de TI poderiam ser estabelecidas a partir do ciclo AvaliaçãoDireção-Controle proposto pela ISO/IEC 38500 (2008, p. 7), a saber:

\section{Avaliação:}

- A direção deve analisar e fazer o julgamento sobre o uso atual e futuro da TI, incluindo estratégias, propostas e acordos de fornecimento.

- Na avaliação do uso da TI, os diretores devem considerar as pressões internas e/ou externas que atuam sobre os negócios, bem como a evolução tecnológica, as tendências econômicas e sociais, e as influências políticas.

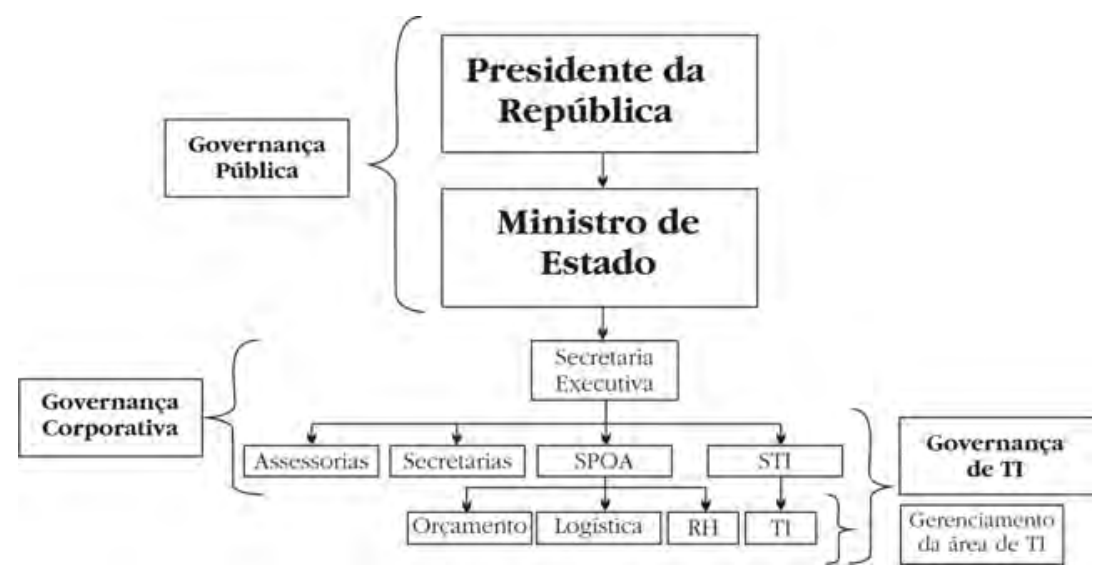

Fonte: Elaboração própria

Figura 1: Proposta de estrutura hierárquica para governança de TI no setor público brasileiro 
- A direção deve realizar avaliações contínuas, garantindo a constante melhoria nos processos.

- A direção deve ter ciência das atuais e futuras necessidades do negócio - os objetivos atuais e futuros que a organização deve atingir.

Direção:

- A direção deve atribuir responsabilidades e participar da preparação e execução de planos e políticas. Os planos devem definir a direção dos investimentos em projetos de TI e em operações de TI. As políticas devem estabelecer um comportamento racional no uso da TI.

- A direção deve assegurar que a transição de projetos para o ambiente de produção esteja devidamente planejada e gerida, bem como esteja considerando os impactos nos negócios, nos procedimentos operacionais, nos sistemas existentes e na infraestrutura de TI.

- A direção deve incentivar uma cultura de boa governança de TI na organização, determinando aos gestores subordinados $\mathrm{O}$ fornecimento de informações gerais sobre a aplicação de boas práticas em conformidade com os seis princípios da boa governança relacionados na ISO/IEC 38500.

Controle:

- A direção deverá acompanhar, por meio de sistemas de medição adequados, o desempenho da TI, garantindo que o desempenho esteja em conformidade com os planos, especialmente no que diz respeito aos objetivos do negócio.

- A direção também deve se certificar de que está em conformidade com as obrigações externas (regulamentação, legislação vigente, termos contratuais) e normas internas de trabalho.

Para a norma internacional ISO/IEC 38500 (2008), a responsabilidade pelos aspectos específicos da TI pode ser delegada aos gerentes dentro da hierarquia da organização, porém a responsabilidade pelo uso e distribuição da TI em uma organização, de modo eficaz, eficiente e aceitável, permanece com os diretores e não pode ser delegada.

\section{Mecanismos de relacionamento}

Os mecanismos de relacionamento complementam a governança de TI, incorporando as relações da TI com as demais áreas da organização e com seus usuários. Tais mecanismos garantem o funcionamento da estrutura criada para a TI e dos processos estabelecidos (HAEs \& Grembergen, 2008, p. 24).

\section{$2^{\text {a }}$ Diretriz - Implantação de meca- nismos de relacionamento}

Para Weill e Ross (2006, p. 87), os mecanismos de governança de TI, quando bem concebidos, bem compreendidos e transparentes, promovem comportamentos desejáveis em termos de TI. Nesse contexto, os autores enumeram 15 dos mecanismos mais comuns de governança de TI, agrupados em três tipologias - estruturas de tomada de decisões, processos de alinhamento e abordagens de comunicação, a saber:

- estruturas de tomadas de decisão;

- comitê administrativo executivo ou sênior;

- comitê de liderança de TI, compreendendo o executivo de TI; de TI;

- equipes de processo com membros

- gerentes de relacionamento entre negócios e TI;

- conselho de TI, compreendendo executivos de negócios e TI;

- comitê de arquitetura de TI;

- comitê de aprovação de orçamento;

- processos de alinhamento; 
- acompanhamento de projetos de TI e recursos consumidos;

- acordos de nível de serviço;

- rastreamento formal do valor de negócio da TI;

- arranjos de cobrança reversa;

- abordagens de comunicação;

- trabalho com gerentes que não seguem as regras;

- comunicados da alta gerência;

- escritório da governança de TI; e

- portais web e intranets para TI.

Todos os mecanismos propostos são aplicáveis ao setor público brasileiro. Assim, os 15 mecanismos propostos por Weill e Ross (2006), em pesquisa sobre boas práticas de governança de TI, realizada em 255 empresas de todo o mundo, incluindo várias do setor público, tornamse ferramentas legítimas para utilização nos processos de implantação da governança de TI na administração pública federal.

\section{Processos de GTI}

Processos de GTI abordam a tomada de decisão estratégica, o planejamento estratégico de TI e os frameworks de monitoramento, controle e processos (HAES E Grembergen, 2008, p. 24).

\section{$3^{\text {a }}$ Diretriz - Evolução da maturi-} dade dos principais processos de TI, de modo sustentável

O nível de maturidade do processo de TI deve descrever as boas práticas que garantam legitimidade aos procedimentos e sejam compatíveis com o perfil e capacidade dos recursos da área de TI de um órgão público com características inerentes àquele nível.

Desse modo, a decisão de melhorar a maturidade em determinado processo corresponderia ao cumprimento de procedimentos já legitimados por outros órgãos e disponíveis para serem incorporados ao segmento de TI, com as adaptações julgadas necessárias. Concluída a transição, que significa a adoção das práticas e procedimentos pela equipe de TI, esse novo caso de sucesso seria publicado para, de modo legítimo, ser utilizado por outros órgãos em suas iniciativas de elevação da maturidade de seus processos.

Em conformidade com a Teoria Institucional, nesta proposta duas palavraschave se destacam: legitimidade e maturidade. A busca da legitimidade requer ações distintas para o envolvimento do nível estratégico e do nível operacional, pois, embora tanto os dirigentes estratégicos quanto os dirigentes operacionais devam se adaptar ao novo modelo de governança de TI, as abordagens são diferentes em cada caso.

Para o nível estratégico da organização, a legitimidade se inicia com o reconhecimento da importância estratégica da TI para a organização. Além disso, será necessário contar com a elevação simultânea do nível de maturidade da governança corporativa da organização, pois será mais difícil elevar a maturidade da GTI de uma organização pública sem o correspondente amadurecimento da sua governança corporativa.

Para o nível operacional, o foco deverá estar concentrado na capacitação e habilitação nos aspectos de liderança da gerência média, por meio de identificação de perfis adequados e formação específica, com ênfase administrativa e gerencial e menos técnica.

A dupla abordagem middle-up/middledown torna-se uma das principais premissas para implantação da governança de TI no setor público brasileiro, pois corresponde à atuação do governante de TI no nível estratégico da organização que, de um lado, acompanha as estratégias e estabelece políticas e diretrizes sobre o uso da TI na organização e, de outro, exerce o monitoramento e acompanhamento da mudança 
organizacional junto ao nível operacional da TI, garantindo que a gerência da área de TI se processe dentro das melhores práticas e de modo compatível com o perfil e capacidade de sua equipe. Tal característica orientou o nome do método (GTI-MUD - as primeiras letras de governança de tecnologia da informação, Middle - Up - Down).

$\mathrm{Na}$ Figura 2, apresenta-se uma representação esquemática do método GTI-MUD, tendo as ações isomórficas como balizadores da evolução entre os níveis de maturidade de um processo que envolve a incorporação de procedimentos e as boas práticas no âmbito da governança corporativa, governança de TI e gerenciamento da área de TI.

\section{$4^{a}$ Diretriz - Introdução de procedi- mentos e práticas já legitimados na APF \\ O método GTI-MUD não pretende rediscutir a segmentação da área de TI em processos e domínios, por isso pode ser}

complementado com qualquer framework de processos de TI existente. Como proposta para implantação da GTI nas organizações públicas brasileiras, entende-se que o framework Cobit 4.1, por ter sido muito utilizado por gestores de TI e órgãos de controle (TCU, 2008a e 2008b), estaria legitimado para servir de base à descrição das ações isomórficas que orientam as atividades dos agentes responsáveis pelos procedimentos e boas práticas que viabilizarão a elevação do nível de maturidade em cada processo.

Desse modo, para cada nível de maturidade dos 34 processos do Cobit 4.1 (ITGI, 2007), propõe-se que sejam identificadas ações isomórficas miméticas, normativas e coercitivas que legitimem os procedimentos de governança de TI, alinhando-os ao nível estratégico da organização (middle-up) e ao nível operacional da área de TI (middle-down).

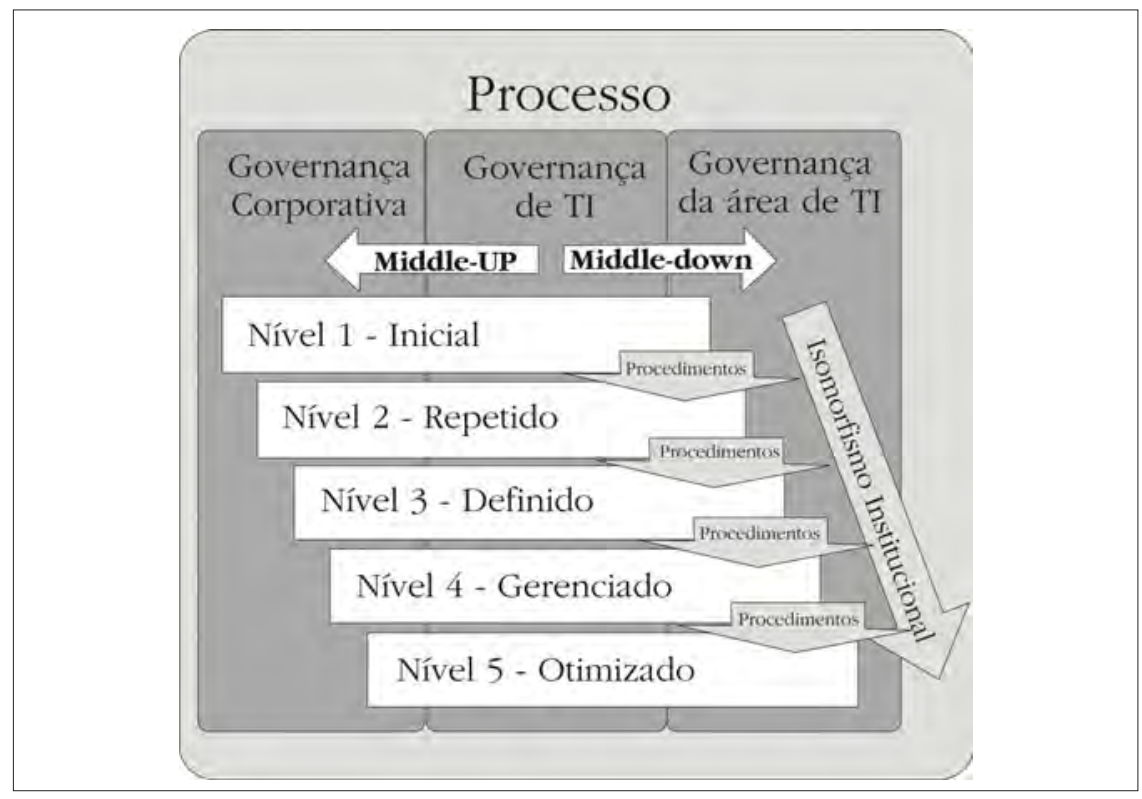

Fonte: Elaboração própria

Figura 2: Representação esquemática do método GTI-MUD 
Como no Nível 0 o processo é inexistente, o primeiro nível utilizado para relacionar as ações isomórficas será o Nível 1 - Inicial/Ad Hoc. Assim, em cada nível serão descritos procedimentos e boas práticas que legitimarão os agentes envolvidos na implantação ou melhoria do processo.

A título de exemplo dos conceitos do GTI-MUD, utilizar-se-á o processo PO1 - Definir um Plano Estratégico de TI do Domínio Planejamento e Organização do Cobit 4.1 -, para descrever as ações isomórficas institucionais necessárias para elevação do nível de maturidade de 1 para 2.

A proposta do Método GTI-MUD para alcançar o nível 1 de maturidade de modo sustentável, considerando ações já legitimadas em outros órgãos, é apresentada no Quadro 1 (ver página seguinte), que descreve as ações com orientação Middle-Up, envolvendo o governante de TI e as principais autoridades do órgão; e orientação Middle-Down, que envolve a relação entre o governante de TI e as equipes responsáveis pelo gerenciamento da área de TI.

Exemplos de aplicação do GTI-MOD, com ações isomórficas para a maioria dos processos que envolvem as recomendações do TCU, registradas no Acórdão $1603 / 2008$, estão disponíveis no endereço http://www.wikigov.net/.

\section{Conclusão}

O objetivo deste trabalho foi o desenvolvimento de um conjunto de diretrizes que, de forma sustentável, possibilitem a introdução de boas práticas e procedimen- tos de governança de TI na APF, transpondo as dificuldades inerentes aos processos de mudança no setor público.

As justificativas para realização dessa pesquisa se pautam nos reiterados registros de fragilidades na governança da área de TI dos órgãos e entidades da APF, efetuados pelo Tribunal de Contas da União, por meio de diversos acórdãos.

Neste trabalho, estabeleceram-se orientações básicas para implantação da governança de TI no setor público brasileiro, que consideraram as características institucionais dos órgãos públicos e a tendência à homogeneização por meio do isomorfismo mimético, normativo e coercitivo proposto em postulados da Teoria Institucional.

As diretrizes para implantação da governança de TI na APF permitem realizar, de modo sustentável, a incorporação de boas práticas e procedimentos nas áreas de TI dos órgãos públicos, pois consideram características isomórficas e a necessidade de legitimidade e maturidade como fatores de mudança.

Também devem-se considerar as diretrizes replicáveis, pois independem das características da organização pública (tamanho, poder da União do qual participa, volume de recursos que administra etc.) ou das características do framework de governança adotado (Cobit, Itil etc.).

Por fim, o mais importante, as diretrizes para implantação da governança de TI são exequíveis, pois consideram a incorporação de práticas e procedimentos já validados por órgãos com nível de maturidade mais elevado, transpondo as resistências a mudanças, típicas de organizações do setor público.

(Artigo recebido em agosto de 2012. Versão final em dezembro de 2012). 
Quadro 1: GTI-MUD - Nível Inicial/Ad Hoc

\begin{tabular}{|c|c|}
\hline \multicolumn{2}{|c|}{ Orientação Middle-Up } \\
\hline Ações isomórficas miméticas & Justificativa \\
\hline $\begin{array}{l}\text { Analisar o Plano Estratégico de TI } \\
\text { (PETI) de outros órgãos públicos. }\end{array}$ & $\begin{array}{l}\text { Esse procedimento permite a avaliação da qualidade e } \\
\text { abrangência dos planos publicados por outros órgãos. }\end{array}$ \\
\hline $\begin{array}{l}\text { Visitar órgãos públicos que tenham o } \\
\text { processo de elaboração de Peti ama- } \\
\text { durecido. }\end{array}$ & $\begin{array}{l}\text { Esse procedimento é importante para identificar as boas prá- } \\
\text { ticas de implantação do processo e quantificar o esforço } \\
\text { operacional a ser despendido na tarefa. }\end{array}$ \\
\hline Ações isomórficas normativas & Justificativa \\
\hline $\begin{array}{l}\text { Treinamento em elaboração de plane- } \\
\text { jamento estratégico específico para os } \\
\text { gestores de TI e seus substitutos. }\end{array}$ & $\begin{array}{l}\text { Esse procedimento amplia o conhecimento a respeito dessa } \\
\text { ação gerencial, bem como aproxima os gestores que têm pro- } \\
\text { blemas comuns, mas níveis de maturidade distintos, em uma } \\
\text { sala de aula, com possibilidades favoráveis de compartilha- } \\
\text { rem boas práticas de implementação de planos estratégicos } \\
\text { de TI. }\end{array}$ \\
\hline $\begin{array}{l}\text { Definição de um padrão de plano es- } \\
\text { tratégico de TI. }\end{array}$ & $\begin{array}{l}\text { Esse procedimento, de responsabilidade da SLTI, permite a } \\
\text { padronização dos planos, o estabelecimento da estrutura mí- } \\
\text { nima de informações e a apresentação de orientações básicas } \\
\text { para seu preenchimento. }\end{array}$ \\
\hline Ações isomórficas coercitivas & Justificativa \\
\hline $\begin{array}{l}\text { Estabelecer a obrigatoriedade de } \\
\text { publicação do planejamento estraté- } \\
\text { gico de TI no sítio do órgão, na Internet. }\end{array}$ & $\begin{array}{l}\text { Esse procedimento permite a análise comparativa da qualidade } \\
\text { e abrangência dos planos por parte de entidades de controle } \\
\text { externo, interno e pelo controle social. Também facilita o } \\
\text { compartilhamento das boas práticas e a identificação de órgãos } \\
\text { com processos maduros para realização de visitas técnicas. }\end{array}$ \\
\hline \multicolumn{2}{|c|}{ Orientação middle-down } \\
\hline Ações isomórficas miméticas & Justificativa \\
\hline $\begin{array}{l}\text { Conscientização dos líderes de equipe } \\
\text { acerca da importância do plane- } \\
\text { jamento de TI: estratégico, tático e } \\
\text { operacional. }\end{array}$ & $\begin{array}{l}\text { Esse procedimento permite a introdução de boas práticas } \\
\text { durante as reuniões periódicas com os líderes ou por meio } \\
\text { de palestras proferidas por especialistas. }\end{array}$ \\
\hline $\begin{array}{l}\text { Realização do planejamento das ativi- } \\
\text { dades do governante de TI. }\end{array}$ & $\begin{array}{l}\text { Esse procedimento serve para demonstrar que a autoridade } \\
\text { máxima da TI faz planejamento de suas atividades e constitui } \\
\text { fator de motivação para toda a equipe operacional na realiza- } \\
\text { ção de suas tarefas. }\end{array}$ \\
\hline $\begin{array}{l}\text { Enfatizar os casos de sucesso e as boas } \\
\text { práticas adotadas por uma ou mais } \\
\text { equipes operacionais. }\end{array}$ & $\begin{array}{l}\text { Esse procedimento permite que o gestor de TI ressalte os } \\
\text { ganhos advindos com o procedimento adotado e valorize a } \\
\text { adoção do procedimento. }\end{array}$ \\
\hline Ações isomórficas normativas & Justificativa \\
\hline $\begin{array}{l}\text { Treinamento em planejamento para os } \\
\text { líderes de equipe e para servidores res- } \\
\text { ponsáveis pela elaboração do plane- } \\
\text { jamento de TI. }\end{array}$ & $\begin{array}{l}\text { Esse procedimento amplia o conhecimento a respeito dessa } \\
\text { ação gerencial e permite sua aplicação nas atividades diárias } \\
\text { das equipes. }\end{array}$ \\
\hline $\begin{array}{l}\text { Estabelecer a disciplina de planeja- } \\
\text { mento estratégico de TI nas seleções } \\
\text { de novos servidores do órgão. }\end{array}$ & $\begin{array}{l}\text { Esse procedimento possibilita que os novos servidores do } \\
\text { órgão, por já terem conhecimento em planejamento estraté- } \\
\text { gico de TI, influenciem os mais antigos na adoção de boas } \\
\text { práticas relacionadas a essa ação gerencial. }\end{array}$ \\
\hline Ações isomórficas coercitivas & Justificativa \\
\hline $\begin{array}{l}\text { Estabelecer, formalmente, reunião pe- } \\
\text { riódica, no mínimo mensal, para dis- } \\
\text { cutir os projetos da área de TI com os } \\
\text { líderes de equipe. }\end{array}$ & $\begin{array}{l}\text { Esse procedimento permite ao gestor de TI adotar práticas de } \\
\text { controle de prazo, escopo, recursos humanos etc., para que } \\
\text { possa orientar cada líder de projeto na adoção de práticas de } \\
\text { planejamento e acompanhamento de seus projetos. }\end{array}$ \\
\hline
\end{tabular}

Fonte: Elaboração própria 


\section{Referências bibliográficas}

Ali, S., \& Green, P. IT Governance Mechanisms in Public Sector Organisations: An Australian Context. Journal of Global Information Management, 15(4), 41-63. 2007. Acesso em: 19 de janeiro de 2012. Disponível em: http:/ / www.igi-global.com/Bookstore/Article. aspx?'TitleId $=3660$.

BARRETT, P. Corporate Governance - More than Good Management. CPA South Australia Annual Congress.2001. Acesso em: 19 de janeiro de 2012. Disponível em: http:/ anao.gov.au/uploads/documents/Corporate_Governance_More_than_Good_ Management.pdf

Brown, A., \& Grant, G. Framing the Frameworks: A Review of IT Governance Research. Communications of the Association for Information Systems, 15, 696-712. 2005. Acesso em: 18 de janeiro de 2012. Disponível em: http:/ /www.sims.monash.edu.au/subjects/ims3012/ resources/IT\%20Governance.pdf.

Cavalcanti, A. S. As principais deliberações do TCU sobre Tecnologia da Informação. Seminário: Tecnologia Da Informação: Controle Externo Em Ação. 2008. Acesso em: 18 de janeiro de 2012. Disponível em: http:/ / portal2.tcu.gov.br/portal/page/portal/ TCU/eventos/documentos_eventos?evento $=171$.

Dimaggio, P. \& Powell, W. The Iron Cage Revisited: Institutional Isomorphism and Collective Rationality in Organizational Fields. American Sociological Review, 48, 147-160. 1983. Acesso em: 19 de janeiro de 2012. Disponível em: http://www.jstor.org/stable/ 2095101.

EisenhardT, K. Agency - and Institutional - Theory Explanations: The case of retail sales compensation. Academy of Management Journal, 31(3), 488-511. 1988. Acesso em: 19 de janeiro de 2012. Disponível em: http://www.jstor.org/stable/256457.

FLeTCher, M. Five Domains of Information Technology Governance for Consideration by Boards of Directors. 2006. Dissertação de Mestrado, University of Oregon, Portland, Oregon, USA. Acesso em: 19 de janeiro de 2012. Disponível em: http://aim.uoregon.edu/ research/pdfs/2006-fletcher.pdf.

Greenwood, R. \& Hinings, C. Understanding Radical Organizational Change: Bringing together the Old and the New Institutionalism. Academy of Management Review, 21(4), 1022-1054, 1996. Acesso em: 19 de janeiro de 2012. Disponível em: http:/ /www.jstor.org/ stable/259163.

Grembergen, W., Haes, S. \& Guldentops, E. Structures, processes and relational mechanisms for IT governance. Strategies for Information Technology Governance. London: Idea Group Publishing, 2004.

Guldentops, E. Governing Information Technology through COBIT. Strategies for Information Technology Governance. London: Idea Group Publishing, 2004.

Guldentops, E. The Rule of Four of IT Governance. Information System Control Journal, 6. 2007. Acesso em: 19 de janeiro de 2012. Disponível em: http:/ /www.isaca.org/Journal/ Past-Issues/2007/Volume-6/Documents/jpdf0706-the-rule-of-four.pdf. 
Haes, S. \& Grembergen, W. Analysing the Relationship Between IT Governance and Business/IT Alignment Maturity. Proceedings Of The 41st Hawail International Conference On System Sciences. 2008. Acesso em: 19 de janeiro de 2012. Disponível em: http://csdl2.computer.org/comp/proceedings/hicss/2008/3075/00/30750428.pdf. Henderson, J. \& Venkatraman, N. Strategic alignment: Leveraging information technology for transforming organizations. IBM Systems Journal, 28 (2), 472-484, 1999. Acesso em: 19 de janeiro de 2012. Disponível em: http://ieeexplore.ieee.org/Xplore/ login.jsp?url $=$ http $\% 3 \mathrm{~A} \% 2 \mathrm{~F} \% 2$ Fieeexplore.ieee.org $\% 2$ Fstamp $\% 2$ Fstamp.jsp $\%$ 3Ftp\%3D\%26arnumber\%3D5387096\&authDecision=-203.

InTERNATIONAL Organization for Standardization \& International Electrotechnical Commission International Standard ISO/IEC 38500 - Corporate governance of information technology. 2008. Acesso em: 19 de janeiro de 2012. Disponível em: http://www.iso.org/ iso/iso_catalogue/catalogue_tc/catalogue_detail.htm?csnumber $=51639$.

IT Governance Institute. Board Briefing on IT Governance. 2003. Acesso em: 19 de janeiro de 2012. Disponível em: http://www.isaca.org/Knowledge-Center/Research/ Documents/BoardBriefing/26904_Board_Briefing_final.pdf.

IT Governance Institute. COBIT 4.1. 2007. Acesso em: 19 de janeiro de 2012. Disponível em: https://www.isaca.org/Knowledge-Center/cobit/Documents/CobiT-4.1Brochure.pdf.

JACOBSON, D. Revisiting IT Governance in the Light of Institutional Theory. 42TH HAWAII INTERNATIONAL CONFERENCE ON SYSTEM SCIENCES. IEEE Computer Society. 2009. Acesso em: 19 de janeiro de 2012. Disponível em: http:// csdl2.computer.org/comp/proceedings/hicss/2009/3450/00/09-10-02.pdf.

Luftman, J. N. Managing the information technology resource: Leadership in the information age. New Jersey: Prentice Hall Publisher, 2004.

Lunard, G. Um Estudo Empírico e Analítico do Impacto da Governança de TI no Desempenho Organizacional. 2008. Tese de Doutorado em Administração. Universidade Federal do Rio Grande do Sul, Porto Alegre, RS, Brasil. Acesso em: 19 de janeiro de 2012. Disponível em: http://www.lume.ufrgs.br/bitstream/handle/10183/13248/ 000642838.pdf? sequence $=1$.

Meyer, J. \& Rowan, B. Institutionalized Organizations: Formal Structure as Myth and Ceremony. The American Journal of Sociology, 83, 1977. Acesso em: 19 de janeiro de 2012. Disponível em: http://www.jstor.org/stable/2778293.

Peterson, R. R. Integration Strategies and Tactics for Information Technology Governance. Strategies for Information Technology Governance. London: Idea Group Publishing. 2004.

Rocheleau, B. \& Wu, L. Public versus private information systems: Do they differ in important ways? A review and empirical test. American Review of Public Administration, 32(4), 379-397, 2002. Acesso em: 19 de janeiro de 2012. Disponível em: http:// arp.sagepub.com/cgi/content/abstract/32/4/379.

Rossetto, C. \& Rossetto, A. Teoria Institucional e Dependência de Recursos na Adaptação Organizacional: uma visão complementar. RAE-eletrônica, 4(1), 2005. Acesso em: 19 de janeiro de 2012. Disponível em: http:/ /www16.fgv.br/rae/redirect.cfm?ID=1869. 
Sambamurthy, V. \& Zmud, R. Arrangements for Information Technology Governance: A Theory of Multiple Contingencies. MIS Quarterly, 23, 261-290, 1999. Acesso em: 19 de janeiro de 2012. Disponível em: http://www.jstor.org/stable/249754.

Sсотт, R. The Adolescence of Institutional Theory. Administrative Science Quarterly, 32, 493-511, 1987. Acesso em: 19 de janeiro de 2012. Disponível em: http:/ /www.jstor.org/ stable/2392880.

Sethibe, T., Campbell, J. \& Mcdonald, C. IT Governance in Public and Private Sector Organisations: Examining the Differences and Defining Future Research Directions. 18th Australasian Conference On Information Systems. 2007. Acesso em: 19 de janeiro de 2012. Disponível em: http:/ /www.acis2007.usq.edu.au/assets/papers/137.pdf.

Tribunal de Contas da União . Acórdão 2471/2008-Plenário. Acesso em: 19 de janeiro de 2012. Disponível em: http://contas.tcu.gov.br/portaltextual/MostraDocumento? $\operatorname{lnk}=\% 28$ AC-2471-46/08-P $\% 29 \% 5$ bnumd $\% 5$ d $\% 5 b B 001, B 002, B 012 \% 5 \mathrm{~d}$.

Tribunal de Contas da União. Acórdão 1603/2008-Plenário. Acesso em: 19 de janeiro de 2012. Disponível em: http://contas.tcu.gov.br/portaltextual/MostraDocumento? $\operatorname{lnk}=\% 28$ AC-1603-32/08-P $\% 29 \% 5$ bnumd $\% 5 \mathrm{~d} \% 5 \mathrm{bB} 001, \mathrm{~B} 002, \mathrm{~B} 012 \% 5 \mathrm{~d}$.

Tribunal de Contas da União. Acórdão 2308/2010-Plenário. Acesso em: 18 de janeiro de 2012. Disponível em: http://www.ticontrole.gov.br/portal/pls/portal/docs/ 1604920.PDF.

Tribunal de Contas da União. Acórdão 2584/2012-Plenário. Acesso em: 22 de janeiro de 2013. Disponível em: http://www.tcu.gov.br/Consultas/Juris/Docs/CONSES/ TCU_ATA_0_N_2012_38.pdf.

Webb, P., Pollard, C. \& Ridley, G. Attempting to Define IT Governance: Wisdom or Folly? 39th Hawait International Conference On System Sciences. Ieee Computer Society. 2006. Acesso em: 19 de janeiro de 2012. Disponível em: http://csdl2. computer.org/comp/proceedings/hicss/2006/2507/08/250780194a.pdf.

WeILl, P. Don't Just Lead, Govern: How Top Performing Firms Govern IT. MIS Quarterly Executive, 8, 2004. Acesso em: 19 de janeiro de 2012. Disponível em: http:/ / web.mit.edu/ cisr/working\%20papers/cisrwp341.pdf.

Weill, P. \& Ross, J. W. Governança de TI, Tecnologia da Informação. São Paulo: Editora M. Books do Brasil, 2006. 


\section{Resumo - Resumen - Abstract}

Diretrizes para implantação da governança de tecnologia da informação no setor público brasileiro à luz da Teoria Institucional

José Geraldo Loureiro Rodrigues e João Souza Neto

Neste trabalho, foi desenvolvido um conjunto de diretrizes que, de forma sustentável, possibilitam a introdução de boas práticas e procedimentos de governança de TI na administração pública federal (APF), transpondo as dificuldades inerentes aos processos de mudança no setor público. Para tanto, foi estabelecida uma metodologia de pesquisa que contemplou o levantamento bibliográfico dos conceitos de governança corporativa, governança de TI, gerenciamento da área de TI, no âmbito do setor privado e do setor público, e das teorias organizacionais, para identificação de explicações aplicáveis aos processos de mudança no setor público. Também se submeteu um questionário aos gestores de TI das principais organizações da APF, para identificação do nível de conformidade com as recomendações do TCU, consubstanciadas nos acórdãos 1603/2008, 2308/2010 e 2584/2012, e das possíveis causas que levaram ao cumprimento ou descumprimento dessas recomendações. Por fim, estabeleceram-se orientações básicas para implantação da governança de TI no setor público brasileiro, que considerou as características institucionais dos órgãos públicos e a tendência à homogeneização por meio do isomorfismo mimético, normativo e coercitivo, proposto em postulados da Teoria Institucional.

Palavras-chave: governança de tecnologia da informação; setor público; Teoria Institucional

Directrices para la implantación de la gobernanza de tecnología de la información en el sector público brasileño a la luz de la Teoría Institucional

José Geraldo Loureiro Rodrigues y João Souza Neto

En este trabajo fue desarrollado un conjunto de directrices que, de una manera sostenible, posibilita la introducción de mejores prácticas y de procedimientos de gobierno de TI en la $\mathrm{APF}$, trasponiendo las dificultades inherentes a los procesos de cambios en el sector público. Por lo tanto, se estableció una metodología de investigación que incluyó una revisión bibliográfica de los conceptos de gobierno corporativo, gobierno de TI, gestión del área de TI, en el sector privado y en el público, y de las teorías de las empresas, para la identificación de las explicaciones aplicables a los procesos de cambio en el sector público. También se presentó un cuestionario a los gestores de TI de los principales organismos de la administración pública federal, para la identificación del nivel de conformidad con las recomendaciones del TCU, consolidadas en las normas 1603/2008, 2308/2010 y 2584/2012, y de las posibles causas que llevaron a su cumplimiento o no. Por último, se establecieron directrices básicas para la implantación del gobierno de TI en el sector público brasileño, que consideró las características institucionales de los organismos públicos y la tendencia a la homogeneización a través de isomorfismo mimético, normativo y coercitivo, postulados propuestos en la teoria institucional.

Palabras clave: Gobierno de tecnología de la información; sector público; Teoría Institucional 
Guidelines for the implementation of IT Governance in the Brazilian Federal Public Administration based on Institutional Theory

José Geraldo Loureiro Rodrigues and João Souza Neto

In this work, a set of guidelines for the sustainable implementation of best practices and procedures of IT Governance in the Brazilian Federal Public Administration was developed, overcoming the inherent difficulties found in the change processes of the public sector. In order to accomplish this, a research methodology was defined and it was composed of bibliographic research of the concepts of Corporate Governance, IT Governance, and IT Management, in the scope of the public and private sectors, and of the organizational theories, to help identify explanations for these inherent difficulties. A questionnaire was submitted to IT Managers of Brazilian Federal Public Administration organizations to identify the level of compliance with the recommendations of the Court of Audit, described in the Acórdãos 1603/ $2008,2308 / 2010$, and $2584 / 2012$, and to identify the possible causes that led to the fulfillment or nonfulfillment of these recommendations. At last, basic guidelines for the implementation of IT Governance in the Brazilian Federal Public Administration were proposed, taking into consideration the institutional characteristics of the public organizations and their tendency to become homogeneous by means of mimetic, normative, and coercive isomorphism, defined by Institutional Theory.

Keywords: IT governance; public sector; Institutional Theory

José Geraldo Loureiro Rodrigues

Mestre em Gestão do Conhecimento e da Tecnologia da Informação pela Universidade Católica de Brasília (UCB). Contato: geraldo@loureiroweb.com

João Souza Neto

Doutor em Engenharia Elétrica pela Universidade de Brasília (UnB) e Professor do curso de Mestrado em Gestão do Conhecimento e da Tecnologia da Informação pela Universidade Católica de Brasília (UCB). Contato: joaon@ucb.br 